\title{
Multiple Stressors and Ecological Complexity Require a New Approach to Coral Reef Research
}

\author{
Linwood H. Pendleton $^{1 *}$, Ove Hoegh-Guldberg ${ }^{2,3}$, Chris Langdon ${ }^{4}$ and Adrien Comte ${ }^{5}$ \\ ${ }^{1}$ LabexMER, University of Brest, IUEM/AMURE, and Nicholas Institute, Duke University, Brest, France, ${ }^{2}$ Global Change \\ Institute, University of Queensland, Brisbane, QLD, Australia, ${ }^{3}$ Australian Research Council Centre for Excellence in Coral \\ Reef Studies, Brisbane, QLD, Australia, ${ }^{4}$ Department of Marine Biology and Ecology, RSMAS, University of Miami, Miami, FL, \\ USA, ${ }^{5}$ University of Brest, IUEM/AMURE, Brest, France
}

Ocean acidification, climate change, and other environmental stressors threaten coral reef ecosystems and the people who depend upon them. New science reveals that these multiple stressors interact and may affect a multitude of physiological and ecological processes in complex ways. The interaction of multiple stressors and ecological complexity may mean that the negative effects on coral reef ecosystems will happen sooner and be more severe than previously thought. Yet, most research on the effects of global change on coral reefs focus on one or few stressors, pathways or outcomes (e.g., bleaching). Based on a critical review of the literature, we call for a regionally targeted strategy of mesocosm-level research that addresses this complexity and provides more realistic projections about coral reef impacts in the face of global environmental change. We believe similar approaches are needed for other ecosystems that face global environmental change.

Keywords: coral reefs, multiple stressors, mesocosm-level research, climate change, ocean acidification

Major changes are occurring in the state of the world's oceans (Hoegh-Guldberg et al., 2014; Pörtner et al., 2014). Scientists have amassed evidence that changing global conditions in the ocean threaten the health and, in some cases, the existence of the world's most biodiverse marine ecosystem, coral reefs. These threats to coral reefs, in turn, pose serious risks to lives and livelihoods of hundreds of millions of people who depend on coral reefs for food, protection against storms and waves, income and the benefits of coral-based recreation (Burke et al., 2011). Predictions about the impacts of two key elements of global change on corals, increased sea temperature and ocean acidification (OA), are often based on analyses of the historical record (Pandolfi et al., 2011), analysis of field data that attempt to attribute changes at the reef level to only one factor (for a critique, see Iglesias-Prieto et al., 2014) or single organism or single stressor laboratory experiments. Far fewer studies are conducted at a mesocosm scale in which multiple stressors and entire reef systems are considered from an experimental level (e.g., Dove et al., 2013). A recent study (Albright et al., 2016) performs a large scale field experiment by altering a single stressor (increasing $\mathrm{pH}$ ) along a coral reef gradient.

Both scientists and planners have focused disproportionately on simple relationships (Pandolfi et al., 2011), both linear and non-linear (Ries et al., 2010), including thresholds that have been used to model future coral decalcification (Ries et al., 2010; van Hooidonk et al., 2014) and which link individual components of global environmental change to dramatic impacts like coral bleaching, and the dissolution of carbonate shells and reefs. In reality, much smaller increases in sea temperature and OA could adversely affect a wide range of critical ecosystem 
functions, which often interact synergistically, causing impacts that are greater than predicted for each of the stressors on their own (Anthony et al., 2008; Kaniewska et al., 2012; Albright and Mason, 2013; Lürig and Kunzmann, 2015). There is a risk that single or limited pathway approaches may yield projections that significantly underestimate the onset and intensity of the impacts of global change on coral reef ecosystems.

We believe that future research strategies need to address the effects of multiple environmental factors through the numerous and interacting ways that an organism may be affected by these stresses, and via the many different organisms within an ecosystem that may be influenced in complex ways by global environmental changes (Russell et al., 2012). We argue for an approach that focuses on the key interactions and processes that will potentially help us understand and predict the impact of global changes, such as ocean acidification and increased sea surface temperature, on coral reefs and other ecosystems. Such an approach must be strategic, coordinated, and representative of the regional ecological contexts in which the effects of $\mathrm{OA}$ and rising temperature on corals will be played out in the real world.

The effects of ocean acidification on coral reefs has attracted significant attention recently. Ocean acidification has been shown in the laboratory and the field to affect the structure and function of the world's oceans (Yang et al., 2015). Current rates of change in ocean chemistry have no precedent in the past 65 million years if not 300 million years (Hoegh-Guldberg et al., 2014) which will push organisms and ecosystems well out of the range of conditions for which they are adapted. While laboratory experiments will continue to advance our still nascent understanding of the mechanisms by which ocean acidification affects coral reef organisms(Kaniewska et al., 2012; Pan et al., 2015; Stillman and Paganini, 2015), it is also important that the research community develops a research strategy that takes into account realistic rate, scale, and complexity.

Ocean acidification occurs when atmospheric carbon dioxide increases, leading to more $\mathrm{CO}_{2}$ entering the ocean. On entering the water column, $\mathrm{CO}_{2}$ reacts with water to create a weak acid, thereby reducing $\mathrm{pH}$, and decreasing the concentration of carbonate ions (critical for calcification). Previous attempts to project the future impacts of $\mathrm{OA}$ on coral reefs focused narrowly on the balance between the formation (calcification) and dissolution (decalcification) of calcium carbonate, and its effects on reef structure (Pandolfi et al., 2011) and generally don't account for strong multi-stressor interactions. Other factors, like elevated sea surface temperature, appear to work synergistically with OA, greatly enhancing the effect of the individual factors (Rodolfo-Metalpa et al., 2011; Bijma et al., 2013). Exploring the influence of ocean acidification on reef building corals, for example, reveals very different responses when other factors are included (Anthony et al., 2008; Vogel et al., 2015), with evidence of synergistic or antagonistic outcomes between factors like ocean temperature and acidity (e.g., fertilization success Albright and Mason, 2013). More than 60 new studies have appeared in the literature addressing the role of ocean acidification on a mix of marine organisms or natural communities (Yang et al., 2015).

While research that has focused on single variables, such as increased sea surface temperature, or single species, has contributed to our understanding of global change (Eakin et al., 2010), such approaches often fail to address the otherwise complex nature of these systems. There is a risk that these approaches may lead to overly conservative estimates of the scale and speed of onset of the future impacts. It cannot be assumed that complexity will reduce the real impacts of these environmental stressors. Mesocosm experiments in the Great Barrier Reef showed that individual coral colonies maintained positive net calcification rates while the net calcification rates for the larger reef community became strongly negative (Dove et al., 2013). Similarly, in Palau Rock Islands, changes in $\mathrm{pH}$ were found to affect rates of bio-erosion even though many other community characteristics were unaffected (Barkley et al., 2015). This highlights the potential problem of making community level projections based on studies that focus on too narrow a group of organisms within simplified experimental frameworks.

To illustrate the many stressors, pathways, and outcomes by which environmental change can impact coral reef ecosystems, we present a conceptual diagram (Figure 1A) built upon a recent survey by Cinner et al. (2015) to create a basic model of essential reef complexity. The diagram incorporates findings from empirical studies conducted in the laboratory and the field where corals have experienced changes in temperature (bleaching events) and ocean acidification (e.g., near seeps and upwelling). The conceptual model is built around the basic calcification/decalcification pathway (in black) but also illustrates the multiplicity of stresses (Ateweberhan et al., 2013; Breitburg et al., 2015), the numerous pathways of impacts on organisms, and the many organismal components of the system, including people.

Previous analyses of the impacts of ocean acidification on coral reef ecosystems often build on the most basic, foundational relationship-that coral reefs are shaped by the equilibrium between erosion and accretion of calcium carbonate (Figure 1A). Biotic factors (e.g., grazing parrotfish and invertebrates, excavating sponges, endolithic algae) as well as abiotic factors (e.g., storms and ocean chemistry) contribute to the breakdown and dissolution of accreted calcium carbonate. On the other side of the ledger, a range of organisms, from reef building corals to red coralline algae, deposit calcium carbonate that, under the right conditions, ultimately builds the 3-D framework of carbonate reef systems. When these factors are in balance, reefs retain their structure or even increase in size and complexity. These processes of reef construction and destruction have preoccupied investigators trying to understand the potential impacts of ocean acidification for coral reefs as structures. However, a large range of other organisms and interactions are also present within carbonate coral reef systems (Figure 1A). These other organisms and processes drive a large range of other phenomena within coral reefs such as primary productivity, habitat, nutrient cycles, gas exchange, and genetic diversity and connectivity. Global factors, such as increased sea temperature and ocean acidification, combine with each other and local environmental stresses to alter the state of coral reefs by disrupting the physiology, gene expression, and behavior of many organisms within this system, not just corals (Figure 1A). These impacts are made worse by other global scale changes in 
A

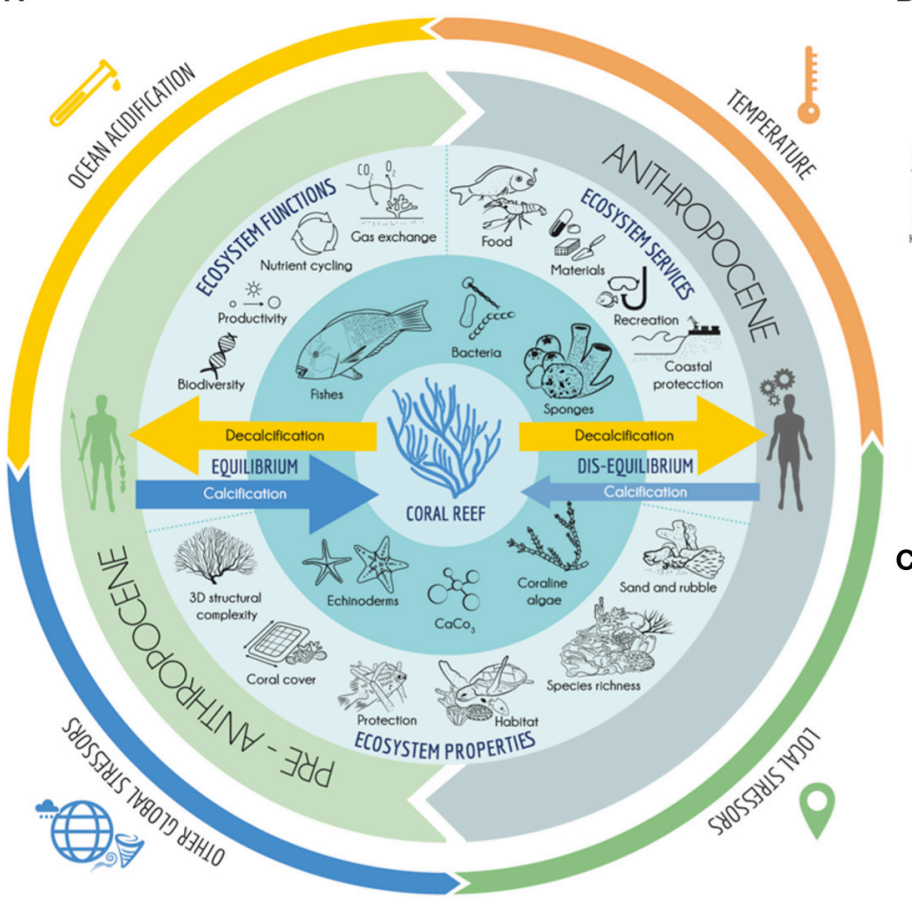

B
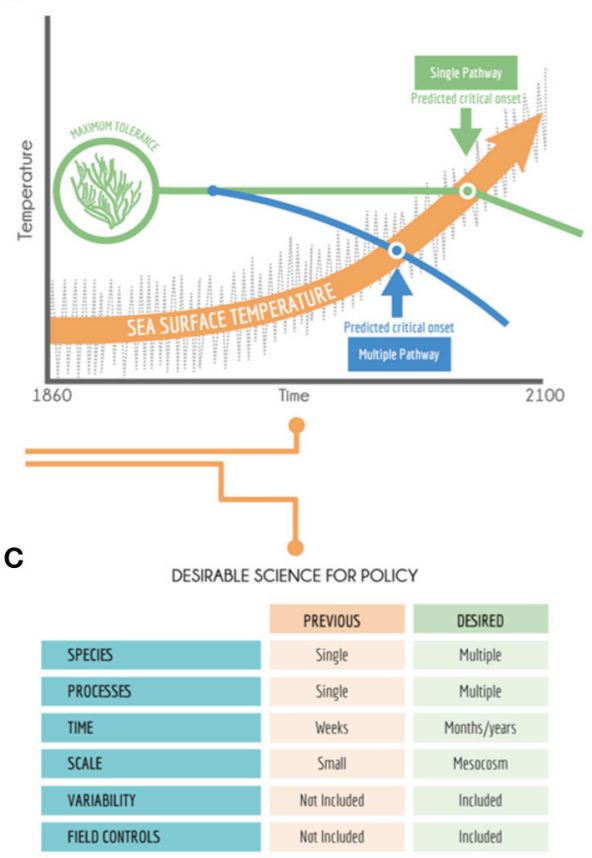

FIGURE 1 | (A) A conceptual framework describing ecological processes that contribute to coral reef growth and maintenance vs. the biological and anthropogenic factors that can work against these processes. The inner circle depicts important coral reef ecosystem constituent species. The next circle represents ecosystem features that are important to people. The next circle, along with the arrows showing calcification and decalcification illustrates that in pre-Anthropocene times coral reefs experienced net growth where calcification probably exceeded decalcification; the balance has been reversed at some time during the Anthropocene. The outermost circle captures key environmental stressors that affect coral reef health and determine whether coral reefs grow or decline. Panel (B) demonstrates how increased ecological sensitivity due to multiple stressors (blue line) can lower the threshold at which sea surface temperature causes harm to coral reefs and thus hastens the onset of damages. Panel (C) shows the dimensions along which new science must be expanded, and how, in order to provide more policy relevant science (inspired by Cinner et al., 2015).

frequency and strength of hurricanes and widening anoxic dead zones.

Ocean acidification has a direct impact on the calcification rates of many corals (Dove et al., 2013; Kaniewska et al., 2015), which has implications for the 3-D structure of coral reefs; reflected in a body of knowledge that has increased significantly over the past 15 years. While there have been many studies on the calcification of corals (see Chan and Connolly, 2013; Kroeker et al., 2013 for reviews), identification of the mechanisms that result in a change in calcification in the field has been complicated by the fact that multiple factors (e.g., elevated temperature and OA) act simultaneously and often synergistically. Anthony et al. (2008), for example, found that the threshold for thermal bleaching was reduced by ocean acidification, indicating that corals became more sensitive to thermal stress when exposed to ocean acidification.

Understanding the functional changes in coral reefs is as important as understanding the impacts on calcification, yet has been neglected in the majority of previous studies of changes to reefs caused by ocean acidification (Pan et al., 2015). While there are a growing number of studies about the effects of OA on processes other than coral calcification and dissolution (e.g., productivity, growth, reproduction), they often are restricted to a small number of organisms and processes relative to the high biological diversity and ecosystem complexity of even the simplest coral reefs (Kroeker et al., 2013). Previous studies also provide very little information on the effect of OA and other factors on the function of microbial organisms and processes that play crucial roles in everything from nutrient cycles to decalcification. Nutrients may play a complicated role in reef structure and have been shown to make corals less sensitive to elevated $\mathrm{CO}_{2}$, even though at the community level they have been shown to stimulate bioeroders. Macro-organisms such as sea cucumbers, fish, and many other organisms also show changes in physiology and behavior due to OA which could have important implications for coral reef processes, although the number of studies about this is extremely small (Kroeker et al., 2013).

Finally, the role of humans as prominent drivers of current conditions (i.e., the Anthropocene) needs to be included along more dimensions that normally found in the literature. Prior to the Anthropocene, people had a direct influence on reef functions, through fishing and reef destruction. Presumably, at low levels, these human impacts could occur within the "scope for growth" required to maintain a healthy reef system (HoeghGuldberg, 2014). Increasingly, human activities at the local scale, including direct and indirect impacts such as overfishing, mining, nutrient runoff, and pollution are leading to a net loss of coral reefs and coral reef structure (Burke et al., 2011). Today, people 
worldwide indirectly affect reef state by contributing through actions that cause the release of carbon dioxide and other greenhouse gases that lead to increases in ocean temperature, sea level rise, and ocean acidification (IPCC, 2013).

Human and ecosystem-level adaptation and even some level of evolution could occur if the changes to corals caused by OA were to occur slowly and evenly, with stabilization by mid-to-late century (what we refer to as the soft landing effect, Figure 1B) or if only one environmental factor changed. The integrated, multiple pathways model of reef processes, however, suggests that simple, linear changes in reef systems are unlikely. Under these conditions, transitions are unlikely to be slow or smooth. The combination of multiple stressors acting on a variety of organismal processes in many species of reef organisms could well mean that thresholds are further reduced with the result that the combined impacts of climate change, ocean acidification, storms, and local stressors could occur much sooner than currently thought (Figure 1B) and be abrupt, unpredictable, and more severe than predicted by more simplified approaches.

If we are to have the science needed to understand, mitigate, and adapt to the effects of OA on coral reefs, we have to take bold and coordinated action to build upon traditional laboratory experiments to create new experimental approaches that address the complexity that will determine how coral reefs respond to $\mathrm{OA}$ and other global changes. Given the urgency and complexity associated with this phenomenon, we recognize an important need to build upon single factor approaches to include more strategic coral reef research that addresses the behavior of multiple factors and their interactions, with a stronger focus on coordinated, multi-factorial experiments in the laboratory, new approaches such as the Free Ocean Carbon Enrichment system deployments (Kline et al., 2012), and mesocosm-scale field experiments in addition to, and coordinated with, field experiments. Similarly, the monitoring of the physical, chemical, ecological, and human impacts of OA and related temperatures needs to be coupled with this approach. This level of coordination and attention to complexity is essential if we are to develop a better understanding of the changes and challenges that we currently face as the concentration of carbon dioxide and other greenhouse gases increase rapidly in the atmosphere. Designing field experiments which take into account environmental variability at the full range of scales (and geographies), together with a more representative range of organisms and processes is central to developing the insights needed to create realistic scenarios, and thereby assist in the development of policy and management activities (Figure 1C). Single organism and single factor experiments will continue

\section{REFERENCES}

Albright, R., Caldeira, L., Hosfelt, J., Kwiatkowski, L., Maclaren, J. K., Mason, B. M., et al. (2016). Reversal of ocean acidification enhances net coral reef calcification. Nature 531, 362-365. doi: 10.1038/nature17155

Albright, R., and Mason, B. (2013). Projected near-future levels of temperature and $\mathrm{pCO}_{2}$ reduce coral fertilization success. PLoS ONE 8:e56468. doi: 10.1371/journal.pone.0056468 to be important in unlocking the way organisms respond to environmental change. When combined with mesocosm-scaled field experiments, especially those that are located to reflect regional differences in the responses of coral reefs, these varied approaches could help to unlock the effects that multiple stressors and pathways have on the way global change will affect coral reefs.

We caution planners that univariate expectations about the potential changes that could await coral reef systems, indeed all marine ecosystems, may not reflect the complex and nonlinear outcomes that could result. In reality, environmental changes that affect coral reefs will not occur along single dimensions of stress. Changes in coral reef ecosystems caused by environmental change are likely to be highly unpredictable, more rapid, and potentially more substantial than we now anticipate. A combination of laboratory and field experiments, especially those that look at naturally occurring suites of environmental change, are needed to unlock these complexities and the effects of multiple stressors. Complexity and the role of multiple stressors and pathways need to be directly incorporated into experimentation and monitoring to better understand how complex systems such as coral reefs are likely to change in response to multiple and rapidly changing global factors. The only certain way to avoid these unwanted consequences, and a constantly changing set of interacting factors, is by stabilizing the Earth's atmosphere and climate as soon as possible.

\section{AUTHOR CONTRIBUTIONS}

All authors listed, have made substantial, direct and intellectual contribution to the work, and approved it for publication.

\section{FUNDING}

This paper was supported by a grant from the Prince Albert II of Monaco Foundation. Linwood Pendleton and Adrien Comte's time also were supported by "Laboratoire d'Excellence" LabexMER (ANR-10-LABX-19), the Region of Brittany, and co-funded by a grant from the French government under the program "Investissements d'Avenir." OH's time was funded partially by the Australian Research Council. Vanessa Gonzàlez Ortiz created Figure 1. Publication fees were paid for by The Nature Conservancy's Mapping Ocean Wealth Project.

\section{ACKNOWLEDGMENTS}

The authors would like to acknowledge the SESYNC Project on Ocean Acidification for stimulating ideas for this manuscript. 
Barkley, H. C., Cohen, A. L., Golbuu, Y., Starczak, V. R., DeCarlo, T. M., and Shamberger, K. E. F. (2015). Changes in coral reef communities across a natural gradient in seawater pH. Sci. Adv. 1, e1500328. doi: 10.1126/sciadv.1500328

Bijma, J., Pörtner, H.-O., Yesson, C., and Rogers, A. D. (2013). Climate change and the oceans - what does the future hold? Mar. Pollut. Bull. 74, 495-505. doi: 10.1016/j.marpolbul.2013.07.022

Breitburg, D. L., Salisbury, J., Bernhard, J. M., Cai, W.-J., Dupont, S., Doney, S. C., et al. (2015). And on top of all that... Coping with ocean acidification in the midst of many stressors. Oceanography 28, 48-61. doi: 10.5670/oceanog.2015.31

Burke, L., Reytar, K., Spalding, M., and Perry, A. (2011). Reefs at Risk Revisited. Available online at: http://pdf.wri.org/reefs_at_risk_revisited.pdf (Accessed November 26, 2014).

Chan, N. C. S., and Connolly, S. R. (2013). Sensitivity of coral calcification to ocean acidification: a meta-analysis. Glob. Chang. Biol. 19, 282-290. doi: 10.1111/gcb.12011

Cinner, J. E., Pratchett, M. S., Graham, N. A. J., Messmer, V., Fuentes, M. M. P. B., Ainsworth, T., et al. (2015). A framework for understanding climate change impacts on coral reef social-ecological systems. Reg. Environ. Change 1-14. doi: 10.1007/s10113-015-0832-Z

Dove, S. G., Kline, D. I., Pantos, O., Angly, F. E., Tyson, G. W., and HoeghGuldberg, O. (2013). Future reef decalcification under a business-as-usual $\mathrm{CO}_{2}$ emission scenario. Proc. Natl. Acad. Sci. U.S.A. 110, 15342-15347. doi: 10.1073/pnas.1302701110

Eakin, C. M., Morgan, J. A., Heron, S. F., Smith, T. B., Liu, G., Alvarez-Filip, L., et al. (2010). Caribbean corals in crisis: Record thermal stress, bleaching, and mortality in 2005. PLoS ONE 5:e13969. doi: 10.1371/journal.pone.0013969

Hoegh-Guldberg, O. (2014). Coral reefs in the Anthropocene: persistence or the end of the line? Geol. Soc. Lond. Spec. Publ. 395, 167-183. doi: 10.1144/SP395.17

Hoegh-Guldberg, O. R., Cai, E. S., Poloczanska, P. G., Brewer, S., Sundby, K., et al. (2014). "The Ocean," in Fifth Assessment Report of the Intergovernmental Panel on Climate Change (IPCC) (Cambridge, UK; New York, NY: Cambridge University Press), 1655-1731.

Iglesias-Prieto, R., Galindo-Martínez, C. T., Enríquez, S., and Carricart-Ganivet, J. P. (2014). Attributing reductions in coral calcification to the saturation state of aragonite, comments on the effects of persistent natural acidification. Proc. Natl. Acad. Sci. U.S.A. 111, 300-301. doi: 10.1073/pnas.1318521111

IPCC (2013). “Summary for policymakers," in Climate Change 2013: The Physical Science Basis. Contribution of Working Group I to the Fifth Assessment Report of the Intergovernmental Panel Climate Change (Cambridge, UK; New York, NY: Cambridge University Press), 33.

Kaniewska, P., Campbell, P. R., Kline, D. I., Rodriguez-Lanetty, M., Miller, D. J., Dove, S., et al. (2012). Major cellular and physiological impacts of ocean acidification on a reef building coral. PLoS ONE 7:e34659. doi: 10.1371/journal.pone.0034659

Kaniewska, P., Chan, C. K., Kline, D., Ling, E. Y., Rosic, N., Edwards, D., et al. (2015). Transcriptomic changes in coral holobionts provide insights into physiological challenges of future climate and ocean change. PLoS ONE 10:e0139223. doi: 10.1371/journal.pone.0139223

Kline, D. I., Teneva, L., Schneider, K., Miard, T., Chai, A., Marker, M., et al. (2012). A short-term in situ $\mathrm{CO}_{2}$ enrichment experiment on Heron Island (GBR). Sci. Rep. 2, 1-9. doi: 10.1038/srep00413
Kroeker, K. J., Kordas, R. L., Crim, R., Hendriks, I. E., Ramajo, L., Singh, G. S., et al. (2013). Impacts of ocean acidification on marine organisms: Quantifying sensitivities and interaction with warming. Glob. Chang. Biol. 19, 1884-1896. doi: $10.1111 /$ gcb.12179

Lürig, M., and Kunzmann, A. (2015). Effects of episodic low aragonite saturation and elevated temperature on the physiology of Stylophora pistillata. J. Sea Res. 99, 26-33. doi: 10.1016/j.seares.2015.01.005

Pan, T.-C. F., Applebaum, S. L., and Manahan, D. T. (2015). Experimental ocean acidification alters the allocation of metabolic energy. Proc. Natl. Acad. Sci. U.S.A. 112, 4696-4701. doi: 10.1073/pnas.1416967112

Pandolfi, J. M., Connolly, S. R., Marshall, D. J., and Cohen, A. L. (2011). Projecting coral reef futures under global warming and ocean acidification. Science 333, 418-422. doi: 10.1126/science. 1204794

Pörtner, H., Schmidt, D. N., Roberts, J. M., and Rost, B. (2014). "Ocean systems," in Climate Change 2014: Impacts, Adaptation, and Vulnerability. Part A: Global and Sectoral Aspects. Contribution of Working Group II to the Fifth Assessment Report of the Intergovernmental Panel on Climate Change (Cambridge, UK; New York, NY: Cambridge University Press), 411-484.

Ries, J. B., Cohen, A. L., and McCorkle, D. C. (2010). A nonlinear calcification response to $\mathrm{CO}_{2}$-induced ocean acidification by the coral Oculina arbuscula. Coral Reefs 29, 661-674. doi: 10.1007/s00338-010-0632-3

Rodolfo-Metalpa, R., Houlbrèque, F., Tambutté, É., Boisson, F., Baggini, C., Patti, F. P., et al. (2011). Coral and mollusc resistance to ocean acidification adversely affected by warming. Nat. Clim. Chang. 1, 308-312. doi: 10.1038/ncli mate1200

Russell, B. D., Harley, C. D. G., Wernberg, T., Mieszkowska, N., and Connell, S. D. (2012). Predicting ecosystem shifts requires new approaches that integrate the effects of climate change across entire systems. Glob. Change Biol. 8, 30-32. doi: 10.1098/rsbl.2011.0779

Stillman, J. H., and Paganini, A. W. (2015). Biochemical adaptation to ocean acidification. J. Exp. Biol. 218, 1946-1955. doi: 10.1242/jeb.115584

van Hooidonk, R., Maynard, J. A., Manzello, D., and Planes, S. (2014). Opposite latitudinal gradients in projected ocean acidification and bleaching impacts on coral reefs. Glob. Chang. Biol. 20, 103-112. doi: 10.1111/gcb.12394

Vogel, N., Meyer, F. W., Wild, C., and Uthicke, S. (2015). Decreased light availability can amplify negative impacts of ocean acidification on calcifying coral reef organisms. Mar. Ecol. Prog. Ser. 521, 49-61. doi: 10.3354/meps11088

Yang, Y., Hansson, L., and Gattuso, J.-P. (2015). Data compilation on the biological response to ocean acidification: an update. Earth Syst. Sci. Data Discuss. 8, 889-912. doi: 10.5194/essdd-8-889-2015

Conflict of Interest Statement: The authors declare that the research was conducted in the absence of any commercial or financial relationships that could be construed as a potential conflict of interest.

Copyright (c) 2016 Pendleton, Hoegh-Guldberg, Langdon and Comte. This is an open-access article distributed under the terms of the Creative Commons Attribution License (CC BY). The use, distribution or reproduction in other forums is permitted, provided the original author(s) or licensor are credited and that the original publication in this journal is cited, in accordance with accepted academic practice. No use, distribution or reproduction is permitted which does not comply with these terms. 